3. Kalayanarooj S, Vaughn DW, Nimmannitya S, et al. (1997) Early clinical and laboratory indicators of acute dengue illness. J Infect Dis. 176(2): 313-21.

4. Kalayanarooj $S$ Nimmannitya $S$, Suntayakorn S, et al. (1999) Can Doctors Make an Accurate Diagnosis of Dengue Infections at an Early Stage? Dengue Bulletin Volume 23.

5. Dinh The T, Le Thi Thu T, Nguyen Minh D, et al. (2012) Clinical features of dengue in a large vietnamese cohort: intrinsically lower platelet counts and greater risk for bleeding in adults than children. PLoS Negl Trop Dis. 6(6):e1679.

6. WHO. Dengue haemorrhagic fever. Diagnosis, treatment, prevention and control. $2^{\text {nd }}$ Edition (1997). WHO Geneva, pp. 12-23

7. Nimmannitya S. (1997) Dengue hemorrhagic fever: diagnosis anh management, in Dengue and Dengue hemorragic fever, edited by Gubler D.J and Kuno G, Cab International, UK, pp. 133-145.

8. Phuong CX, Nhan NT, Kneen R, et al. (2004). Clinical diagnosis and assessment of severity of confirmed dengue infections in Vietnamese children: is the world health organization classification system helpful? Am J Trop Med Hyg.70(2): 172-9.

9. Gubler DJ. (1998) Dengue and dengue hemorrhagic fever. Clin Microbiol Rev.;11(3):48096. Review

\title{
SO SÁNH TÁC DUUNG TRÊN TUẦN HOÀN VÀ CÁC TÁC DỤNG KHÔNG MONG CỦA ONDANSETRON VỚI DEXAMETHASON HOĂC METOCLOPRAMID ĐỂ DỰ PHÒNG NÔN, BUỒN NÔN TRONG VÀ SAU MỔ LẤY THAI
}

\section{TÓM TẮT}

Mục tiêu: So sánh tác dụng trên tuần hoàn và các tác dụng không mong muốn của Ondansetron với Dexamethason hoặc Metoclopramid để dự phòng nôn, buồn nôn trong và sau mổ lấy thai. Đối tượng, phương pháp nghiên cứu: Nghiên cứu được tiến hành trên 90 sản phụ ASA I-II (20 - 41 tuổi), có chì định mổ lấy thai, vô cảm bằng gây tê tủy sống, tại khoa Gây mê hồi sức, Bệnh viện phụ sản Hà Nội từ tháng 1 đến tháng 7 năm 2020. Các sản phụ được phân loại ngẫu nhiên thành ba nhóm bằng nhau: Nhóm $O$ được tiêm tĩnh mạch $8 \mathrm{mg}$ Ondansetron, nhóm $\mathrm{D}$ được tiêm tĩnh mạch $8 \mathrm{mg}$ Dexamethason, nhóm $M$ được tiêm tĩnh mạch $10 \mathrm{mg}$ Metoclopramid. Các tác dụng không mong muốn được đánh giá liên tục trong và 24 giờ đâu sau mổ. Kết quả: Tỷ lệ tụt huyết áp của các bệnh nhân ở nhóm Ondansetron là $36,7 \%$; của nhóm Dexamethasone là $56,7 \%$ và của nhóm Metoclopramide là 53,3\%, khác biệt có ý nghĩa thống kê $(p<0,05)$. Tỷ ngứa của ba nhóm lần lượt là: $36,7 \%$ so với $56,7 \%$ và $43,3 \%$, khác biệt không có ý nghĩa thống kê $(p>0,05)$. Không gặp trường hợp nào bị đau thượng vị, rối loạn nhịp tim hoặc bị hội chứng ngoại tháp... Kểt luận: Tỷ lệ tụt huyết áp của các bệnh nhân ở nhóm Ondansetron thấp hơn có ý nghĩa thống kê so với nhóm Dexamethason hoặc nhóm Metoclopramid với $p<0,05$. Tỷ lệ các tác dụng không mong muốn khác như: ngứa, đau thượng vị... không có sự khác biệt giữa ba nhóm. Không gặp trường hợp nào bị rối loạn nhịp tim hoặc bị hội chứng ngoại tháp.

\footnotetext{
${ }^{1}$ Trường Đại họ Y HN

${ }^{2}$ Bênh viên Đa khoa tỉnh Vînh Phúc

Chịu trách nhiệm chính: Nguyễn Đức Lam

Email: lamgmhs75@gmail.com

Ngày nhận bài: 21.12.2020

Ngày phản biện khoa họ: 29.01.2021

Ngày duyệt bài: 2.2.2021
}

\section{Nguyễn Đức Lam ${ }^{1}$, Vũ Văn Hiệp ${ }^{2}$}

Tư khóa: Gây tê tủy sống, Ondansetron, Dexamethason, Metoclopramid, mổ lấy thai.

\section{SUMMARY \\ THE COMPARISON OF THE CIRCULATION EFFECTS AND SIDE EFFECTS OF \\ ONDANSETRON WITH DEXAMETHASONE OR METOCLOPRAMIDE TO PREVENT VOMITING, NAUSEA DURING AND AFTER CESAREAN SECTION}

Objective: To compare the effects on circulation and side effects of Ondansetron with Dexamethasone or Metoclopramide to prevent vomiting, nausea during and after cesarean section. Methods: This study was conducted on 90 ASA I-II women (20 - 41 years old) indicated cesarean section with spinal anesthesia, at the Department of Anesthesiology, Hanoi Obstetrics and Gynecology Hospital from January to July 2020. The patients were randomly divided into three similar groups: Group $\mathrm{O}$ was administered intravenously $8 \mathrm{mg}$ of Ondansetron, group $D$ with $8 \mathrm{mg}$ of Dexamethasone and group $M$ with $10 \mathrm{mg}$ of Metoclopramide. The side effects were recorded continuously during surgery and the first 24 hours after surgery. Results: The rate of hypotension in the Ondansetron group was $36.7 \%$; in the Dexamethasone group was $56.7 \%$ and in the Metoclopramide group was $53.3 \%$, the difference was statistically significant ( $p<0.05$ ). The pruritus rates of the three groups were $36.7 \%, 56.7 \%$ and $43.3 \%$, respectively, the difference was not statistically significant ( $p>0.05)$. No cases of epigastric pain, arrhythmia or extrapyramidal syndrome ...

Conclusion: The rate of hypotension in the Ondansetron group was statistically significantly lower than in the Dexamethasone group or the Metoclopramide group with $p<0.05$. The rates of other side effects such as: pruritus, epigastric pain... did not differ between the three groups. There was no case of arrhythmia or extrapyramidal syndrome. 
Keywords: Spinal anesthesia, Ondansetrone, Dexamethasone, Metoclopramide, cesarean section.

\section{I. ĐẶT VẤN ĐỀ}

Nôn, buồn nôn trong và sau mổ là tác dụng không mong muốn của các phương pháp vô cảm, đặc biệt, tỷ lệ nôn, buồn nôn khá cao sau gây tê tủy sống để mổ lấy thai, nó không chỉ gây khó chịu cho bệnh nhân, gây khó khăn cho phẫu thuật viên trong mổ mà còn gây tăng đau đớn sau mổ, mất nước điện giải, nặng hơn có thể gây bục vết mổ... Vì vậy, dự phòng nôn, buồn nôn trong và sau mổ lấy thai là cần thiết giúp tăng sự hài lòng của bênh nhân và góp phần vào thành công của phẫu thuật. Ondansetron, Dexamethason, Metoclopramid là các thuốc dự phòng nôn đã được sử dụng từ lâu và đã được nghiên cứu trên thế giới, tuy nhiên, chưa có nhiều nghiên cứu ở Việt Nam về các thuốc này, đặc biệt, nghiên cứu về các tác dụng không mong muốn. Vì vậy, chúng tôi tiến hành nghiên cứu này, nhằm mục tiêu: So sánh các tác dụng không mong muốn của Ondansetron với Dexamethason hoặc Metoclopramid để dự phòng nôn, buồn nôn trong và sau mổ lây thai.

II. ĐỐI TƯợNG VÀ PHƯƠNG PHÁP NGHIÊN CứU

1. Đối tượng nghiên cứu. Bao gồm 90 bệnh nhân có chỉ định mổ lấy thai, vô cảm bằng gẩy tê tủy sống tại Khoa Gây mê hồi sức Bệnh viện phụ sản Hà Nội từ tháng 11 năm 2019 đến tháng 7 năm 2020.

- Tiêu chuẩn lựa chọn: Bệnh nhân đồng ý tham gia nghiên cứu, không có chống chỉ định GTTS, ASA I- II, không sử dụng thuốc chổng nôn khác trước và trong phẫu thuật.

- Tiêu chuẩn loại trừ: Bệnh nhẩn từ chối tham gia nghiên cứu, có chống chỉ định với Ondansetron, Dexamethason hoặc Metoclopramid.

2. Phương pháp nghiên cứu: Thử nghiệm lâm sàng ngẫu nhiên có so sánh.

\subsection{Phương pháp tiến hành}

a, Chuẩn bị bệnh nhân: Giải thích rõ những ưu điểm và các tác dụng không mong muốn có thể gặp của ba loại thuốc dự phòng nôn được sử dụng trong nghiên cứu, lựa chọn các bệnh nhân đủ tiêu chuẩn tham gia nghiên cứu.

b, Chuẩn bị các phương tiện nghiên cứu. Thuốc dự phòng nôn: Ondansetron $8 \mathrm{mg} / 4 \mathrm{ml}$ hãng Hameln Pharm GmbH của Đức. Dexamethason $4 \mathrm{mg} / \mathrm{ml}$ và Metoclopramid (biệt dược: Vincomid) của Công ty cổ phần Dược phẩm Vĩnh Phúc (Việt Nam). Ngoài ra, chuẩn bị đầy đủ các thuốc sử dụng trong gây mê hồi sức để mổ lấy thai. c, Các bước tiến hành. Sau khi chọn mẫu, những bệnh nhân đủ tiêu chuẩn lựa chọn vào nghiên cứu được rút thăm ngẫu nhiên, chia thành 3 nhóm:

- Nhóm O $(n=30)$ được tiêm tĩnh mạch $8 \mathrm{mg}$ Ondansetron, nhómD $(n=30)$ được tiêm tĩnh mạch $8 \mathrm{mg}$ Dexamethasone, nhóm $M(n=30)$ được tiêm tĩnh mạch $10 \mathrm{mg}$ Metoclopramide thực hiện trước khi GTTS 5 - 10 phút.

Các bệnh nhân được gây tê tủy sống ở L3-4, tư thế nằm nghiêng trái, sử dụng thuốc tê

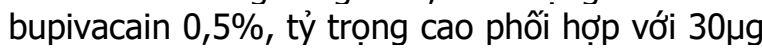
Fentanyl. Liều thuốc tê bupivacain được tính theo chiều cao của bệnh nhân: Cao < $150 \mathrm{~cm}$ : $7 \mathrm{mg}$, từ $150-160 \mathrm{~cm}: 8 \mathrm{mg}$, Cao $>160 \mathrm{~cm}: 9 \mathrm{mg}$.

2.2. Các thông số theo dõi. Các thời điểm theo dõi: Trong mổ theo dõi tần số tim, huyết áp trung bình, độ bão hòa oxy trong máu động mạch SP02: 2 phút/lần trong mổ cho đến khi mồ xong. Sau mổ theo dõi các chỉ số trên 1 giờ/lần trong 6 giờ đầu, 4-6 giờ/lần trong các giờ tiếp theo mổ (T0: trước khi gây tê tủy sống, T1-T20: sau gây tê tủy sống 1 phút - 20 phút). Tất cả các tác dụng không mong muốn của ba loại thuốc dự phòng nôn sử dụng sẽ được theo dỗi liên tục trong 24 giờ đầu sau.

\subsection{Một số tiêu chuẩn áp dụng trong} nghiên cứu

- Tiêu chuẩn đánh giá mức độ nôn và buồn nôn dựa theo thang điểm của KlockgetherRadke: Chia 4 mức đô

- Bảng điểm yếu tố nguy cơ nôn và buồn nôn theo thang điểm Apfel:

2.4. Các chỉ tiêu nghiên cứu.

- Đặc điểm chung của bệnh nhân:

+ Tuổi, chiều cao, cân nặng, ASA, BMI

+ Thời gian mổ, liều lượng ephedrinđã dùng trong mô.

+ Mức độ phong bế cảm giác tối đa, Mức độ mất máu trong mổ.

+ Apgar của trẻ sơ sinh, Nhịp tim và huyết áp trung bình trong mổ.

- Một số tác dụng không mong muốn của ba nhóm. Đau đâu, ngứa, di ứng, đau thượng vị...

2.5. Xử lý số liệu: Số liệu xử lý trên phần mềm SPSS 16.0. Giá trị $p<0,05$ được coi là sự khác biệt có ý nghĩa thống kê.

2.6. Vấn đề đạo đức trong nghiên cứu. Nghiên cứu đã được phê duyệt bởi Hội đồng đạo đức, Bệnh viện Phụ sản Hà Nội và tuân thủ theo các nguyên tắc về đạo đức trong nghiên cứu y sinh học. 
III. KẾT QUẢ NGHIÊN CỨU

1. Đăc điểm chung của đối tượng nghiên cứu và gây mê hồi sức

Bảng 1. Đặc điểm chung của đôî́t tượng nghiên cứu và gây mê hồi sức

\begin{tabular}{|c|c|c|c|c|}
\hline Chỉ số Nhóm & $\begin{array}{c}\text { Nhóm } 0 \\
n=30\end{array}$ & $\begin{array}{c}\text { Nhóm D } \\
n=30\end{array}$ & $\begin{array}{c}\text { Nhóm M } \\
n=30\end{array}$ & $\mathbf{P}$ \\
\hline $\begin{array}{c}\text { Tuối (năm) } \\
\min -\max \end{array}$ & $\begin{array}{c}30,1 \pm 5,3 \\
(20-41)\end{array}$ & $\begin{array}{c}28,4 \pm 4,2 \\
(21-36)\end{array}$ & $\begin{array}{c}28,3 \pm 4,2 \\
(20-38)\end{array}$ & $>0,05$ \\
\hline $\begin{array}{c}\text { Chiều cao (cm) } \\
\text { min - max }\end{array}$ & $\begin{array}{l}156,3 \pm 5,4 \\
(147-168)\end{array}$ & $\begin{array}{l}157,6 \pm 5,1 \\
(148-170)\end{array}$ & $\begin{array}{l}155,7 \pm 5,5 \\
(147-173)\end{array}$ & $>0,05$ \\
\hline $\begin{array}{l}\text { Cân nặng (kg) } \\
\text { min - max }\end{array}$ & $\begin{array}{l}66,3 \pm 9,6 \\
(50-92)\end{array}$ & $\begin{array}{l}67,4 \pm 8,4 \\
(51-83)\end{array}$ & $\begin{array}{l}64,2 \pm 10,4 \\
(45-100)\end{array}$ & $>0,05$ \\
\hline $\begin{array}{ll}\text { ASA \%: } & \text { I } \\
& \text { II } \\
\end{array}$ & $\begin{array}{c}29(96,7) \\
1(3,3)\end{array}$ & $\begin{array}{c}30(100) \\
0\end{array}$ & $\begin{array}{c}29(96,7) \\
1(3,3)\end{array}$ & $>0,05$ \\
\hline $\begin{array}{c}\text { Mức phong bế cảm giác tối đa } \\
\text { T4 } \\
\text { T6 }\end{array}$ & $\begin{array}{c}25(83,3) \\
5(16,7)\end{array}$ & $\begin{array}{l}19(63,3) \\
11(36,7)\end{array}$ & $\begin{array}{c}24(80) \\
6(20)\end{array}$ & $>0,05$ \\
\hline Tỷ lệ BN có tụt huyết áp $\geq 20 \%$ & $8(26,7 \%)$ & $17(56,7 \%)$ & $16(53,3 \%)$ & $>0,05$ \\
\hline Lượng ephedrin sử dụng(mg) & $\begin{array}{l}6,0 \pm 5,6 \\
(0-20)\end{array}$ & $\begin{array}{l}11,0 \pm 5,5 \\
(0-20)\end{array}$ & $\begin{array}{l}9,7 \pm 6,7 \\
(0-20)\end{array}$ & $P^{*}<0,05$ \\
\hline
\end{tabular}

Nhận xét: Không có sự khác biệt có ý nghĩa thống kê giữa 3 nhóm về đặc điểm chung của bệnh nhân nghiên cứu và một số đặc điểm về gây mê hồi sức $(p>0,05)$ trừ lượng ephedrin sử dụng trong mổ của nhóm Ondansetron thấp hơn có ý nghĩa thống kê so với hai nhóm còn lại $(p<0,05)$.

2. Thay đổi về tuần hoàn

*Thay đổi về tần số tim trước và trong mô.

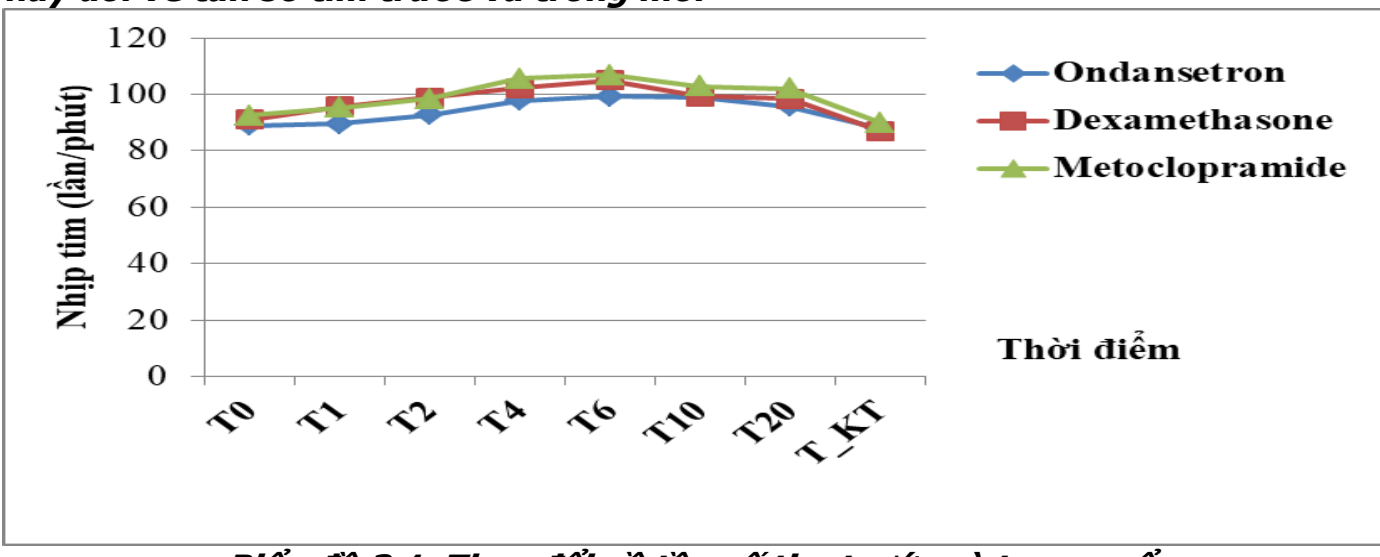

Biểu đồ 3.1. Thay đổi về tần số tim trước và trong mố.

Nhận xét: Tần số tim trung bình của các bệnh nhân trong nghiên cứu tại các thời điểm đánh giá không có sự khác biệt có ý nghĩa thống kê giữa ba nhóm ( $p>0,05)$.

*Thay đổi về huyết áp trung bình (HATB)

Bảng 3.2. Thay đổi về huyết áp trung binh (HATB)

\begin{tabular}{|c|c|c|c|c|}
\hline Thời điểm & $\begin{array}{c}\mathbf{X} \\
\mathbf{\pm ~ S D}\end{array}$ & $\begin{array}{c}\mathbf{D} \\
\mathbf{\pm} \text { SD }\end{array}$ & $\begin{array}{c}\mathbf{M} \\
\mathbf{\pm ~ S D}\end{array}$ & $\mathbf{p}$ \\
\hline T0 & $90,17 \pm 5,1$ & $90,63 \pm 9,7$ & $87,37 \pm 5,2$ & $>0,05$ \\
\hline T1 & $75,73 \pm 5,4$ & $73,53 \pm 7,5$ & $72,1 \pm 13,5$ & $>0,05$ \\
\hline T2 & $76,33 \pm 14,5$ & $74 \pm 14,6$ & $73,9 \pm 13,9$ & $>0,05$ \\
\hline T4 & $80,57 \pm 12,67$ & $77,73 \pm 12,2$ & $78,57 \pm 13,5$ & $>0,05$ \\
\hline T6 & $78,9 \pm 9,09$ & $80,17 \pm 12$ & $82,2 \pm 12,2$ & $>0,05$ \\
\hline T10 & $79,67 \pm 8,1$ & $79,17 \pm 10,5$ & $78,7 \pm 10,9$ & $>0,05$ \\
\hline T20 & $80,47 \pm 8,8$ & $81,9 \pm 9,3$ & $80,83 \pm 11,6$ & $>0,05$ \\
\hline Kết thú́ mố & $84,17 \pm 5,1$ & $83,6 \pm 3,1$ & $82,6 \pm 5,1$ & $>0,05$ \\
\hline Sau mố 1giớ & $85,23 \pm 6,1$ & $84,23 \pm 5,0$ & $83,43 \pm 6,5$ & $>0,05$ \\
\hline
\end{tabular}




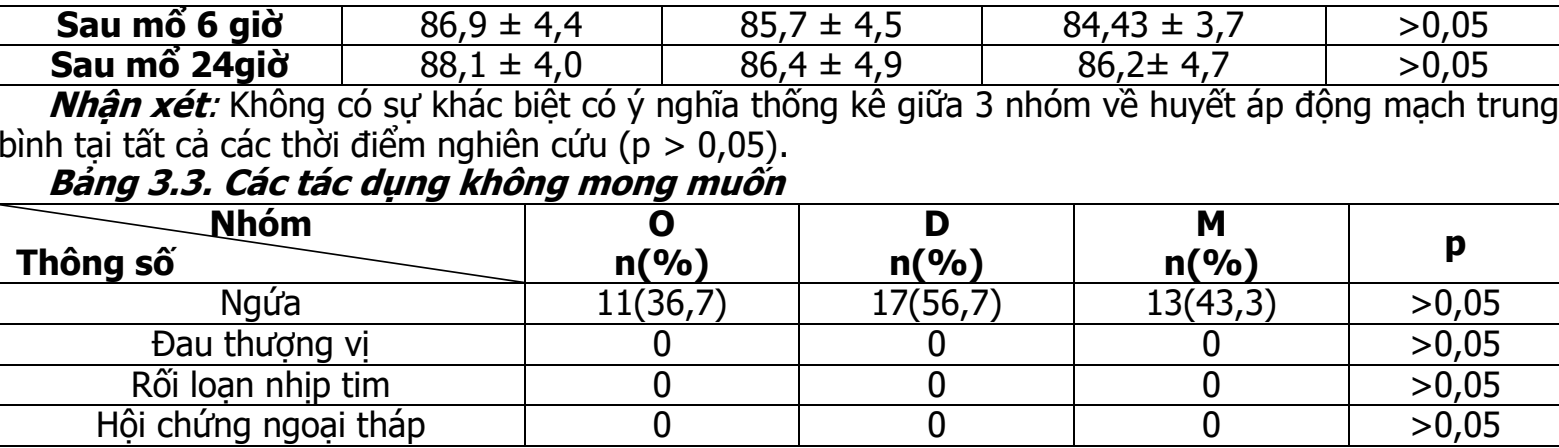

Nhận xét: Không có sự khác biệt có ý nghĩa thống kê về các tác dụng không mong muốn của ba nhóm $(p>0,05)$.

\section{BÀN LUÂ̂N}

Các bênh nhân ở ba nhóm nghiên cứu của chúng tôi đều không có sự khác biệt về đặc đểm chung và các đặc điểm về gây mê hồi sức (bảng 3.1).

1. Thay đổi về tuần hoàn. Nhịp tim trung bình ở thời điểm trước mổ của các bệnh nhân nghiên cứu của chúng tôi tăng nhẹ. Điều này là do liên quan đến những thay đổi sinh lý khi mang thai làm tăng tần số tim người mẹ đồng thời bệnh nhân thấy lo lắng cùng với cảm giác đau do các cơn co tử cung góp phần làm tăng nhị tim. Sau khi lấy thai ra thường ở phút thứ 6 đến phút thứ 10 nhịp tim người mẹ thường cũng tăng do tác dụng phụ của oxytocin. Sau đó nhịp tim xu hướng giảm dần và trở về ổn định ở thời điểm cuối cuộc mổ. Chúng tôi tiếp tục theo dõi nhịp tim sau mổ vì phong bế giao cảm hồi phục chậm hơn phong bế cảm giác sau GTTS. Không có bệnh nhân nào trong nghiên cứu có rối loạn nhịp cần phải can thiệp điều trị. Không có sự khác biệt về thay đổi tần số tim của 3 nhóm nghiên cứu.

Nhịp tim chậm thường thấy sau gây tê tủy sống để mổ lấy thai và đi kèm với nôn, buồn nôn. Đã có nhiêu cáo báo về rối loạn nhịp tim sau gây tê tủy sống. Shen và CS nhận thây tỷ lệ nhịp tim chậm nghiêm trọng (Nhịp tim < 50 lần/phút) là 6,7\% [7]. Nhịp tim chậm < 50lần/phút trong phẫu thuật có thể là dấu hiệu cảnh báo sắp sảy ra trụy tim mạch.Nhịp tim chậm có liên quan đến phong bế giao cảm cao trên mức T5 khi gây tê tủy sống, và phản ứng sinh lý đối với tình trạng giảm tuần hoàn tĩnh mạch trở về dẫn đến tăng trương lực phó giao cảm hoặc kích hoạt các thụ thể trong tâm thất trái(Phản xạ Bezold-Jarisch). Có một số bằng chứng cho thấy sự hoạt hóa các sợi hướng tâm có thể giúp duy trì thời gian đổ đây tâm trương trong thời gian giảm tương đối tuần hoàn tĩnh mạch trở về.
Tụt huyết áp trong mổ lấy thai là một biến chứng thường xuyên của gây tê tủy sống và có liên quan đến các biến cố bất lợi cho mẹ như buồn nôn và nôn và gây hại cho thai nhi. Ngay cả những đợt hạ huyết áp thấp trong thời gian ngắn của người me cũng có thể dẫn đến nhiễm toan thai nhi, chỉ số Apgar thấp hơn và bệnh thiếu máu não cục bộ do thiếu oxy. Mặc dù nhiều nghiên cứu đang được tiến hành, cho đến nay vẫn chưa có biện pháp nào để điều trị đầy đủ hạ huyết áp do gây tê tủy sống, các giải pháp như điều trị bằng chất vận mạch khác nhau, dược lý thay thế như thuốc kháng thụ thể 5-HT3 có thể xem xét cải thiện hơn sự ổn định huyết động. Ondansetron là một chất đối kháng thụ thể 5-HT3 có tính chọn lọc cao. Nó có thể ngăn chặn sự kết hợp của 5-HT với thụ thể 5-HT3 có trong các đầu dây thần kinh phế vị của tâm thất trái và làm giảm phản xạ Bezold-Jarisch, ức chế sự giãn mạch ngoại biên, tăng khối lượng tuần hoàn tĩnh mạch trở về do đó làm giảm tỷ lệ hạ huyết áp [3].

Kết quả này cũng phù hợp với nhiều nghiên cứu chứng minh rằng thuốc đối kháng $5 \mathrm{HT} 3$ có tác dụng ngăn ngừa hạ huyết áp như: Hessen và CS trong nghiên cứu phòng ngừa ha huyết áp do gây tê tủy sống trong mổ lấy thai bằng thuốc đối kháng thụ thể $5 \mathrm{HT} 3$ [4].

Owczuk và $\mathrm{CS}$ quan sát thãy tiêm tĩnh mạch 8 mg ondansetron 5 phút trước khi gây tể tủy sống có thể hạn chế việc giảm huyết áp tâm thu mà không ảnh hưởng đến huyết áp tâm trương hoặc nhịp tim [5].

Sahoo và CS đã báo cáo rằng tiêm tĩnh mạch tiêm $8 \mathrm{mg}$ ondansetron 5 phút trước gây tê tủy sống có thể làm giảm đáng kể tỷ lệ hạ huyết áp, buồn nôn và nôn sau mổ lấy thai dưới gây tê tủy sống và giảm việc sử dụng thuốc co mạch [6].

2. Các tác dụng không mong muốn khác *Rối loạn nhịp tim, hội chứng ngoại 
tháp. Metoclopramide là một loai thuốc ức chế dopaminergic được phân loại là thuốc chống nôn, liêu $10 \mathrm{mg}$ được chứng minh là an toàn cho mẹ và trẻ sơ sinh. Tuy nhiên có báo cáo cho rằng nó có tác dụng phu như: hội chứng ngoai tháp, rối loạn nhịp tim dẫn đến sự thận trọng khi kê đơn. Trong nghiên cứu của chúng tôi không găp trường hợp nào bị rối loạn nhịp tim hoặc có hội chứng ngoại tháp sau sử dụng metoclopramid, tuy nhiên, cần phải lưu ý khi sử dụng thuốc này đối với các bệnh nhân có rối loạn nhịp tim hoặc mắc hội chứng ngoại tháp.

*Ngứa: Ngứa sau gây tê tủy sống để mổ lấy thai thường liên quan đến sử dụng các thuốc họ opioid. Tỷ lệ này tăng cao trên sản phụ có thể do tương tác của estrogen với các thụ thể opioid. Ngứa thường khu trú ở giữa khuôn mặt, mũi và ngực, bên trong dây thân kinh sinh ba. Cơ chế sinh lý bệnh của ngứa chưa thực sự rõ ràng có thể là sự hoạt hóa các thụ thể: $\mu$ opioid trong tủy sổng và não, thụ thể dopaminergic D2, prostaglandin, thụ thể glycine và Gamma-Amino butyric Acid (GABA), 5HT3(Thụ thể có nhiều trong sừng lưng của tủy sống. Sự tương tác giữa opioid và thụ thể $5-\mathrm{HT} 3$ đóng vai trò trong việc tạo ra triệu chứng ngứa trung ương do opioid gây ra). Dựa trên những cơ chế gây ngứa mà có rất nhiều thuốc được dùng để điêu trị ngứa: Kháng thu thể 5HT3(ondansetron 4 hoặc $8 \mathrm{mg}$, granisetron $3 \mathrm{mg}$ ), kháng thụ thể opioid (naloxon truyền 0,25$1 \mathrm{mg} / \mathrm{kg} / \mathrm{h}$ mà không làm giảm hiệu quả giảm đau), thuốc kháng recepter Dopamin D2 (metoclopramide, droperodol), propofol. Trong khi đó các loại thuốc corticoid, thuốc kháng histamin hầu như không có tác dụng điều trị ngứa trung ương. Tỷ lệ các $B N$ trong nghiên cứu của chúng tôi bị ngứa với nhóm $O$ là $36,7 \%$; nhóm $D$ là $56,7 \%$ và nhóm $M$ là $43,3 \%$, tỷ lệ thấp hơn ở nhóm $O$ và $M$, tuy nhiên không có sự khác nhau về tỷ lệ ngứa giữa 3 nhóm nghiên cứu với $p>0,05$. Các bệnh nhân đều ngứa ở mức độ nhẹ không kéo dài nên không cần can thiệp điều trị gì. Kết quả này cũng phù hợp với nghiên cứu của Anahita Hirmanpour và CS khi đánh giá ondansetron và metoclopramide có thể ngăn ngừa ngứa do sulfentanil tủy sống gây ra với tỷ lệ ngứa của ondansetron là $39,5 \%$ và metoclopamide là 42,5\% [2].

*Đau thượng vị. Kết quả nghiên cứu của chúng tôi khổng có bệnh nhân nào bị đau thượng vị. Kết quả này cũng phù hợp với Nguyễn Đình Đức [1]. Có thể do chúng tôi đã khai thác kỹ tiền sử của các bênh nhân tham gia nghiên cứu và đã loại trừ các bệnh nhân bị viêm loét dạ dày, tá tràng.

\section{KẾT LUÂN}

Khi dự phòng nôn, buồn nôn trong và sau mổ lấy thai bằng tiêm tĩnh mạch trước khi gây tê tủy sống: Ondansetron, Dexamethason hoặc Metoclopramid, chúng tôi rút ra kết luận sau: Tỷ lệ tụt huyết áp của các bệnh nhân ở nhóm Ondansetron $(36,7 \%)$ thấp hớn có ý nghĩa thống kê so với nhóm Dexamethasone $(56,7 \%)$ hoặc nhóm Metoclopramide (53,3\%) với $p<0,05$. Tỷ lệ các tác dụng không mong muốn khác như: ngứa, đau thượng vị không có sự khác biệt giữa ba nhóm. Không gặp trường hợp nào bị rối loạn nhịp tim hoặc bị hội chứng ngoại tháp.

\section{TÀI LIÊU THAM KHẢO}

1. Nguyễn Đình Đức và CS. Nghiên cứu tác dụng dư phòng buồn nôn và nôn của dexamethason sau gẩy yê tủy sống mổ lấy thai. Tạp chí Y - Dược học quân sự. 2014;số 5.

2. Anahita Hirmanpour ${ }^{1}$ MSM, Azim Honarmand ${ }^{1}$ Seyede Hamideh Hashemi Yazdi ${ }^{1}$ Arash Pourreza ${ }^{1}$. Ondansetron and Metoclopramide Can Prevent Intrathecal Sufentanil-Induced Pruritus. RESEARCH ARTICLE. 2018;4(1):409-416.

3. S.Farmawy MMR. Effects of intravenous ondansetron and granisetron on hemodynamic changes and motor and sensory blockade induced by spinal anesthesia in parturients undergoing cesarean section. Egyptian Journal of Anaesthesia.29(4):369-374.

4. Heesen M, Klimek M, Hoeks SE, Rossaint R. Prevention of Spinal Anesthesia-Induced Hypotension During Cesarean Delivery by 5Hydroxytryptamine-3 Receptor Antagonists: A Systematic Review and Meta-analysis and Metaregression. Anesthesia and analgesia. Oct 2016;123(4):977-988.

5. Owczuk R, Wenski W, Polak-Krzeminska A, et al. Ondansetron given intravenously attenuates arterial blood pressure drop due to spinal anesthesia: a double-blind, placebo-controlled study. Regional anesthesia and pain medicine. JulAug 2008;33(4):332-339.

6. Sahoo T, SenDasgupta C, Goswami A, Hazra A. Reduction in Spinal-induced Hypotension With Ondansetron in Parturients Undergoing Cesarean Section: A Double-blind Randomized, Placebocontrolled Study. Obstetric Anesthesia Digest. 2013;33(1):31-32.

7. C L Shen 1 YYH, Y C Hung, P L Chen. Arrhythmias during spinal anesthesia for Cesarean section. Canadian Journal of Anaesthesia. 2000 May 2000;47(5):393-397. 